\title{
Т.А. Федорова
}

\section{ИСТОРИЯ КАК СЕМИОЛОГИЧЕСКАЯ СИСТЕМА В ТВОРЧЕСТВЕ ВАЛЬТЕРА СКОТТА}

\begin{abstract}
Рассматриваются семиологическая система базисных значимостей, созданная творчеством Вальтера Скотта, и ее влияние на формирование национальной идентичности Шотландии на рубеже XVIII - начала XIX в. Анализируются исторические предпосылки формирования национального самосознания шотландцев, а также характерные особенности историко-культурного развития региона. Автор приходит к выводу, что Вальтер Скотт в своих произведениях создает путем исторического нарратива систему значимых глубинных образов, формирующих национальное сознание шотландского народа и, как следствие, национальную идентичность.

Ключевые слова: Вальтер Скотт; национальная идентичность; семиологическая система; Шотландия; Пограничье.
\end{abstract}

Современная геополитическая ситуация, в которой доминантным компонентом выступает процесс глобализации, вследствие чего происходит утрата этносом культурного базиса, диктует актуальность изучения механизма формирования национальной идентичности - залога успешного межнационального диалога. В современном социокультурном пространстве процесс формирования и трансформации национальной идентичности становится предметом изучения все большего числа исследователей, поскольку именно в национальной идентичности отражаются состояние социума, его интегрированность, конформность, способность к консолидации и ценностные ориентации. Именно осознание национальной идентичности кроет в себе огромный потенциал для преодоления культурной разобщенности и межнациональных конфликтов.

Учитывая современную геополитическую ситуацию, необходимо особенное внимание сейчас обратить на формирование национального сознания и идентичности - залога успешной международной консолидации сил в борьбе с терроризмом, экстремизмом и национализмом.

Идея формирования национальной идентичности не нова. На протяжении тысячелетий истории человечества идея формирования национальной идентичности наибольшую актуальность приобретала именно в переломные, кризисные этапы исторического развития этноса, народа и государства. Именно в эти моменты особенно востребованным становится исторический нарратив как основное условие стабилизации общества, путем обращения к значимым, с толчки зрения современности, событиям прошлого и опыту их преодоления. По мнению Ролана Барта, исторический нарратив - это система фактов, которая является системой «значимостей», являющееся в обыденном сознании мифом. Нарратив воспринимается как система фактов, будучи на самом деле семиологической системой [1. С. 97]. По сути, исторический нарратив - это конструкт исторического прошлого, т.е. образ возможного прошлого и его предпочтительная интерпретация [2. C. 61]. Именно исторический нарратив формирует се- миологическую систему исторической памяти - необходимый базисный элемент национальной идентичности.

Введение в научный оборот термина «идентичность» принадлежит выдающемуся исследователю в области социальной психологии Эрику Хомбургеру Эриксону [3. С. 23]. Благодаря работам Э. Эриксона стало широко использоваться понятие «кризис идентичности» [4. С. 55], который возникает в условиях глубоких общественных трансформаций. Дальнейшие исследования в этой области Б. Андерсона [5], Э. Геллнера [6], Э. Хобсбаума [7] выявили роль государства и интеллектуальных элит в процессе формирования как общегосударственной, так и этнической идентичности, которая понимается как осознание принадлежности и эмоциональной общности в политическом и общегражданском сообществе, находящемуся в рамках данного государства. Именно эти работы стали базисом конструктивистского направления в исследовании национальной идентичности.

Фундаментальная связь исторической памяти и идентичности была отмечена французским социологом М. Хальбваксом. Основное положение его концепции заключается в том, что каждая социальная группа формирует память о своем прошлом, которая обосновывает ее уникальную идентичность [8. С. 51].

Основной методологический аппарат при исследовании феномена исторической памяти можно найти в работах Жана ле Гоффа [9], П. Рикера [10]. Так, отмечает Поль Рикер, процесс меморилизации предполагает выстраивание разрозненных событий в серии, создание из них различным образом структурированных повествований. История, как писал Георг Вильгельм Фридрих Гегель, собирает в себе части общества и государства, разрозненные в современной действительности [11. C. 57]. Одно и то же событие при этом приобретает разное значение в зависимости от того, в какую сюжетную структуру оно включено [Там же. С. 125].

Большинство современных исследователей отмечают, что в периоды «кризиса идентичности» особенно возрастает интерес к исторической памяти народа. 
В эти периоды данный вид памяти формирует базисную основу стабилизации общества. Память об истории народа формирует чувство сопричастности определенной этнической общности.

Определение «историческая память» в современной научной литературе имеет массу трактовок, что свидетельствует о процессе активного исследования данного феномена. По мнению Ж.Т. Тощенко, историческая память - это выражение процесса организации, сохранения и воспроизводства прошлого опыта народа, страны, государства для возможного его использования в деятельности людей или для возвращения его влияния в сферу общественного сознания [12. С. 3].

Как отмечает А.Н. Медушевский, историческая память представляет собой инструмент политики, который отвечает социальным запросам и имеет возможность влиять на массовое сознание социума [13. С. 50]. По мнению Курта Хюбнера, историческое сознание это интегрирующая сила, которая позволит сплотить народы, не теряя их индивидуальности. История народа и есть то общее дело, которое объединяет индивидов и создает национальное самосознание [14. С. 53].

Необходимым условием преодоления «кризиса идентичности» народа является обращение к его исторической памяти как политических элит, так и интеллектуалов современности. Одной из успешных моделей формирования национальной идентичности может служить трансформация шотландской идентичности на рубеже XVIII-XIX вв. под влиянием интеллектуальной элиты Соединенного Королевства.

В этот период Шотландия претерпевала социальноэкономическую трансформацию, обусловленную быстрым экономическим ростом. Заключение Унии 1707 г. оказало решающее значение для дальнейшего социально-экономического и политического развития Шотландии. Устраняя торгово-экономические и политические барьеры, Уния привела к ускоренному капиталистическому развитию сельскохозяйственной Шотландии.

В 1770 г. Британский парламент принимает закон, по которому шотландские землевладельцы получали право свободно распоряжаться землей и совершать различные земельные операции. Это создало благоприятные условия для развития капитализма в шотландской глубинке - вытеснение мелких арендаторов из сельскохозяйственного производства. В результате промышленного переворота, который приходится в Шотландии на 70-80-е гг. XVIII в., происходило перемещение жителей Хайленда и Пограничья в города Центральной, Южной и Северо-Восточной Шотландии, где они становятся основным резервом свободной рабочей силы [15. С. 96-115]. Именно этот период и есть переломный момент в процессе формирования шотландской национальной идентичности. Национальные черты, особенности языка, фольклор вызывали все больший интерес у широкой публики, поскольку выходцы из Хайленда и Пограничного края становились активными участниками социально-экономического взаимодействия как внутри Шотландии, так и в рамках Соединенного Королевства в целом. Таким образом, учитывая все возрастающую роль шотландцев, формировался социальный запрос на знакомство с «истинно шотландским» характером, особенностями культуры, историческим наследием Великой Шотландии.

Во второй половине XVIII в. возникает политическая востребованность успешной интеграции шотландцев, так как военно-политическая угроза со стороны Хайленда была ликвидирована и, учитывая длительное противостояние между Великобританией и Францией, продолжавшееся с 1689 по 1815 г., государственный заказ был очевиден. Соединенному королевству необходимы были рекруты-шотландцы, регулярно поставляемые в армию ее Величества [16. С. 63].

Влияние как социальной, так и политической востребованности популяризации шотландской национальной культуры не могло не встретить отклик среди шотландской интеллектуальной элиты.

C середины XVIII в. интеллектуальная элита Шотландии обращает исследовательский интерес к наследию шотландских менестрелей, дошедшему в преданиях и старинных балладах. Наиболее интересные работы в этой области принадлежат перу Джеймса Макферсона и епископа Перси. В сборнике Макферсона - поэмах Осиана, как замечает Б.Г. Реизов, было сделано самое главное: гэльское поэтическое мышление переведено на английский язык. Осталось только откинуть то, что было добавлено Макферсоном в угоду его вкусам и вкусам эпохи [17. С. 78]. «Добавления» Макферсона как нельзя лучше демонстрируют протоконструктивистские взгляды шотландской интеллектуальной элиты.

Вальтер Скотт, будучи сыном своего народа, не мог не осознавать необходимость в воссоздании гэльского величия. Именно эпос стал отправной точкой этого процесса. Сборник Вальтера Скотта «Песни шотландской границы», вышедший в 1802-1803 гг., затем неоднократно переиздаваемый, стал апофеозом кельтского возрождения второй половины XVIII - начала XIX в. Баллады, вошедшие в сборник «Песни Шотландской границы», писатель воспринимал не столько как литературное достояние нации, но также как одну из форм исторической памяти Шотландии [18. С. 567]. Благодаря популяризации историко-поэтического наследия Вальтеру Скотту своей работой удалось возродить национальный престиж Шотландии, пострадавший после подписания Унии 1707 г.

В мае 1827 г. у Вальтера Скотта появилась идея написания Истории Шотландии, адресованной его шестилетнему внуку Джону Хью Локхарту. Идея появилась после успеха книги «Избранные истории из истории Англии», автором которой являлся Джон Уилсон Кропер. Но писатель считал, что Джон Кропер недооценивает способность воспринимать исторические события подрастающей молодежью [19. Р. 115]. И это был верный подход. Именно молодое поколение более эмоционально восприимчиво и менее критично к образам прошлого, а выбира- 
емая историческая перспектива позволяет акцентировать внимание только на необходимых событиях, с точки зрения конструктивизма [20. С. 44].

Первый том, который охватывает период между правлениями Макбета (1033-1056) и Союза корон (1603), был завершен в ноябре 1827 г. Он был опубликован 15 декабря 1827 г. с расчетом на рождественский рынок. Весь тираж был продан очень быстро. В мае 1828 г. Скотт согласился написать вторую серию «Рассказов деда». В июле он понял, что он имел так много материала, что он предложил положить конец серии Союзом Англии и Шотландии (1707), затем составил третью серию, которая расширила повествование до конца XVIII в. Вторая серия была завершена 1 сентября 1828 г. и опубликована 27 ноября. Третья серия, которая завершила повествование после событий в Коллодене (1746), появилась 21 декабря 1829 г.

Огромный популярный успех «Рассказов» был подобран почти единодушным одобрением литературного еженедельного лондонского журнала. Атенеум, в частности, приветствовали их как важный вклад в кампанию, чтобы поощрить желание писать для детей. Скотт старался быть беспристрастен, излагая исторические факты, что и послужило основой успеха его произведения. Однако некоторые критики, такие как Эндрю Биссет в «Вестминстер Ревью», осуждали Скотта за то, что он не делал нравственных выводов, излагая историю своей родины [17. С. 351].

Повествование истории Шотландии Вальтер Скотт начинает с завоевания римлянами Туманного Альбиона. Однако им не удалось покорить Горную Шотландию. Как отмечает писатель, народ Горной Шотландии был разделен на шотландцев и пиктов. Он отмечает причины, по которым Британия была разделена на две части: «британскую» и «кельтскую». Скотт пишет: «Римляне вознамерились поставить предел опустошительным набегам пиктов и скоттов на равнинную Британию. С этой целью они насыпали очень длинный земляной вал от западного до восточного побережья острова, чтобы перекрыть скоттам и пиктам все пути на юг. И они построили на валу башни и разместили вдоль него цепь военных лагерей, чтобы по первой тревоге воины могли броситься отбивать приступ» [21. Р. 7].

Действительно, формирование шотландского этноса следует рассматривать со времен Римской Британии, так как важнейший топоним «Пограничье», этническая разобщенность, проявляется именно в этот период истории. C IV в. опасную угрозу представляли племена, населявшие северные территории Шотландии: племена пиктов и скоттов. Римский историк Аммиан Марцеллин отмечает, что в IV в. не было единства даже среди пиктов, потому что они делились на две племенные группы [22. С. 360]. Эти сведения подтверждает Беда Достопочтенный в «Церковной истории народа англов», написанной в начале VIII в. Он указывает, что пикты делились на «северных» и «южных» [23. С. 89].
Повествуя об истоках этнической разобщенности, Вальтер Скотт делает акцент на «дикости» племен Пограничья [21. Р. 7]. Это выверенный прием в духе конструктивистского подхода, так как, по мнению выдающегося социолога Федерика Барта, для восприятия своей идентичности народу необходимо осознание этнических границ внутри социума. Это одно из важнейших условий успешного формирования национального сознания. В свою очередь, существование этнических границ, по мнению ученого, возможно лишь тогда, когда этническая общность наделяется значимыми, отличающими ее от остальных характеристиками, т.е. культурными особенностями [24. С. 24].

Очень интересный контекст прослеживается в повествовании об англо-саксонском завоевании Британии. Автор сообщает, что бриты уступали в мужестве и военной подготовке «диким» скоттам. По словам писателя, бритты оказались совершенно не способны самостоятельно отбиваться от варваров, потому что за время господства римлян они утратили силу и мужество [21. Р. 7]. Именно мужество и храбрость были этнической чертой горцев, позволившей сформировать «Я-концепцию», необходимый базисный компонент этнической идентичности.

Позиция Вальтера Скотта относительно Нормандского завоевания вызывает особый интерес, так как раскрывает отношение писателя к происходящим социальным потрясениям в историческом прошлом его народа. Несмотря на то что норманны несли смерть и разорение, автор объективно признает, что при норманнах Англия стала более мощной страной. «И вы найдете много таких случаев в истории, дорогой ребенок, в которых порадовал промысел божий, что кажется на первый взгляд злом, приносит бесценную пользу» [Ibid. P. 15]. Автор в данном фрагменте делает отсылку в том числе и к событиям 1707 г., формируя у подрастающего поколения положительное отношение к случившемуся.

Образ национального героя, каким является Уильям Уоллес для Шотландии, также является неотъемлемым элементом семиологической системы исторической памяти. Образ национального героя проходит процесс воссоздания образа и его мифологизацию. Особенно актуальным процесс мифологизации национальных героев становится при утрате этносом своего привычного мира и уклада, в период социальных и политических трансформаций [25. С. 120].

Уоллес, отмечает Вальтер Скотт, как каждый пылкий шотландец, с великим возмущением смотрел на присвоение шотландской короны Эдуардом и оскорбления, наносимые английскими вояками его соотечественникам [21. Р. 36]. Образ Уильяма Уоллеса знаковый, так как является одной из основ национальной идентичности - мифологемы национального героя. Именно в критические периоды исторического развития наиболее полно проявляется исторический нарратив образа национального героя, так как он трактуется в соответствии с целями и задачами конкретного исторического периода. 
В плеяду национальных героев в «Рассказах дедушки» входит и Роберт Брюсс. Значимыми чертами, говорящими о его «шотландском духе», были такие, как великодушие, обходительность, образованность [21. Р. 61], т.е. качества, которые были наиболее значимы именно для современников, читателей произведений Вальтера Скотта. Хотя, упоминая о своих предках в ответ на просьбу Геральдической палаты набросать эскиз герба, сэр Скотт отмечал совершенно другие черты национального характера: «До Унии Королевств мои предки, подобно другим джентльменам Пограничного края, триста лет промышляли убийствами, кражами и разбоем...» [26. С. 5].

Говоря о национальных особенностях шотландцев, Скотт пишет, что шотландец осторожный, бережливый, рачительный. У шотландцев встречаются великолепные идеи, которые требуют финансовой поддержки, за неимением этой поддержки они отдаются иностранцам. Именно преодоление экономической отсталости писатель видел целью объединения двух корон и подписания Унии 1707 г. Как пишет автор, «лучше заключить соглашение на основе взаимных преимуществ, чем иметь риск вторжения... Шотландия станет частью империи и, совершенствуя промышленность, достигнет процветания... Английское правительство предложило отправить представителей Шотландии в английский парламент. Это даст возможность Шотландии продвигать свои торговые интересы [21. Р. 66]. Именно социально-экономические интересы Шотландии диктовали ту семиотику, тот исторический нарратив, который был воссоздан в «Рассказах дедушки» при повествовании об Унии двух корон.
Таким образом, становится очевидным, что в исторических реалиях Шотландии конца XVIII - начала XIX в., в период социально-экономических трансформаций, на формирование национальной идентичности шотландцев особое влияние оказало творчество выдающегося писателя-романиста, историка, политического деятеля Вальтера Скотта. Именно Скотт в духе протоконструктивизма, путем обращения к «истинной шотландскости», выстраивает дихотомию «Мы-они», необходимый базисный элемент национальной идентичности. В своих работах писатель воссоздает семиологическую систему исторической памяти, прибегая к историческому нарративу. Народные баллады, национальные характеры, исторические события выстраиваются в систему значимых образов, интерпретируются в соответствии со вкусами и запросами современной действительности - реалиями рубежа XVIII-XIX вв. Возросшая социальная активность шотландцев и их роль в экономической и общественно-политической жизни Соединенного Королевства диктовали необходимость формирования национального сознания - залога успеха и процветания в Британском Содружестве.

Принимая во внимание популярность произведений великого писателя как среди современников, так и на протяжении последующих веков, становится очевидным колоссальное воздействие творчества Вальтера Скотта как на формирование этнического сознания шотландцев, так и внутриполитические и социальные процессы, протекавшие в Великобритании в конце XVIII - начале XIX в.

\section{ЛИТЕРАТУРА}

1. Барт Р. Избранные работы: Семиотика: Поэтика / пер. с фр. ; сост., общ. ред. и вступ. ст. Г.К. Косикова. М. : Прогресс, 1989.616 с.

2. Анкерсмит Ф. Нарративная логика: Семантический анализ языка историков. М. : Идея-Пресс, 2003.360 с.

3. Эриксон Э. Идентичность: юность и кризис. М. : Флинта, 2006. 352 с.

4. Эриксон Э.Г. Кризис идентичности в автобиографической перспективе (фрагмент из книги «История жизни и исторический момент» 1975) // Личность. Культура. Общество. 2008. Вып. 2. С. 48-59.

5. Андерсон Б. Воображаемые сообщества. М. : КАНОН-Пресс ; Кучково поле, 2001. 288 с.

6. Геллнер Э. Нации и национализм / пер. с англ. Т.В. Бредниковой, М.К. Тюнькиной ; ред. и послесл. И.И. Крупника. М. : Прогресс, 1991. $794 \mathrm{c}$.

7. Hobsbawm E. Terence Ranger: The Invention of Tradition. Cambridge : Cambridge University Press, 1992.322 p.

8. Misztal B. Teories of remembering. Maidenhead, Philadelfia : Open University Press, 2003. 190 p.

9. Ле Гофф Ж. Цивилизация средневекового Запада. М. : Прогресс-Академия, 1992. 376 с.

10. Рикер П. Память, история, забвение / пер. с фр. М. : Изд.-во гуманитарной литературы, 2004. 728 с.

11. Гегель Г.В.Ф. Философия истории. СПб. : Наука, 1993. 479 с.

12. Тощенко Ж.Т. Историческое сознание и историческая память: анализ современного состояния // Новая и новейшая история. 2000 . № 4. C. $3-14$.

13. Материалы «круглого стола», проведенного по результатам исследования «Историческая память в российском обществе: состояние и проблемы формирования» / В.Э. Бойко, А.Н. Медушевский, Ж.Т. Тощенко и др. // Социология власти. 2010 . № 6. С. 47-67.

14. Хюбнер К. Нация: от забвения к возрождению. М. : Канон+, 2001. $396 \mathrm{c}$.

15. Зверева Г.И. История Шотландии. М. : Высш. шк., 1987. 207 с.

16. Малкин С.Г. Горная Шотландия конца XVII - первой половины XVIII века и романы Вальтера Скотта // Новая и новейшая история. 2010. № 2. С. 59-71.

17. Реизов Б.Г. Творчество Вальтера Скотта. М. : Худож. лит., 1965. 499 с.

18. Скотт В. Вводные замечания о народной поэзии и о различных сброниках британских (преимущественно шотландских) баллад // Собрание сочинений в двадцати томах / пер. Е.Т. Танка. М. ; Л., 1965. Т. 20. 704 с.

19. Scott W The Journal of Sir Walter Scott. Vol. 1-3. Edinburgh: Oliver \& Boyd, 1939-1946. Vol. 1. 416 p.

20. Васильев А.Г. Культурная память / забвение и национальная идентичность: теоретические основания анализа // Культурная память в контексте формирования национальной идентичности России в XXI веке. М. : Совпадение, 2015. С. 29-57.

21. Scott W. Tales of a Grandfather; Being Stories Taken from Scottish History. Humbly Inscribed to Hugh Littlejohn, Esq. In Three Vols. Cadell \& Co. Edinburgh; Simpkin \& Marshall, London. 1828. Vol. I. 283 p.

22. Глебов А.Г. Римская Британия В III-IV веках и ее падение // Вестник Воронежского государственного университета. 2011. № 2. С. 89-92.

23. Гражданская и религиозная идентичность: вчера, сегодня, завтра / РАН, Ин-т социологии; рук. проекта и отв. ред. Л.М. Дробижева. М. : РОССПЭН, 2013. 483 c. 
24. Шнирельман В.А. Национальные символы, этноисторические мифы и этнополитика // Теоретические проблемы исторических исследований. М. : МГУ, 1999. Вып. 2. С. 118-147.

25. Scott W. The Prose Works of Sir Walter Scott . Edinburgh: Cadell, 1836. Vol. XXV. 255 p.

26. Скотт В. Роб Рой. М. : Дом, 1992. 512 с.

Fedorova Tatyana A. Samara State University of Social Sciences and Education (Samara, Russia). E-mail: Angel_924@mail.ru HISTORY AS A SEMIOLOGICAL SYSTEM IN THE WORKS OF WALTER SCOTT.

Keywords: Walter Scott; national identity; semiological system; Scotland; Borderlands.

In this article the problems of the formation of national identity of the Scots at the turn of XVIII-XIX centuries are examined. Also the author analyses the historical conditions in which the formation of national identity took place and the role played by the Walter Scott's works in this process. This article deals with the problem of integrating the two previously opposing states of England and Scotland, forced under the conditions of the union of 1707 and the subsequent completion of the industrial coup to seek ways to consolidate and at the same time the possibility of preservation of ethnic uniqueness. The purpose of this article is to analyze the impact of the historical narrative in the works of Walter Scott on the formation of the most important symbols of Scottish national consciousness that are the basis of national identity. As the research problem, the author has defined an attempt to assess the degree of narrativeness of the works of Walter Scott, since this factor is crucial in the process of "invention of traditions". The author of the article argues that a necessary condition of overcoming the "crisis of identity" of a nation is an appeal to its historical memory, both by political elites and intellectuals of our time. A transformation of Scottish identity at the turn of XVIII-XIX centuries, under the influence of the intellectual elite of the United Kingdom can serve as one of the successful models of national identity formation. Special attention is paid to the creativity of the first researchers of Scottish cultural heritage. The author notes that since the mid-eighteenth century the intellectual elite of Scotland drew the research interest to the heritage of the Scottish minstrels, preserved in legends and ancient ballads. The most interesting works in this area were written by James MacPherson and Bishop Percy. In the collection of MacPherson - the poems Oceana, as the author notes, was made the most important thing: the Gaelic poetic thinking has been translated into English. In the end the author concludes that Walter Scott, in the spirit of proconstruction, by referring to the "true Scottishness", built up the dichotomy "We-they", the required basic element of national identity. Folk ballads, national characters, historical events, arranged in a system of meaningful images are interpreted in accordance with the tastes and demands of modern reality - the reality of the turn of XVIII-XIX centuries. The increased social activity of the Scots and their role in economic and political life of the United Kingdom necessitated the formation of national consciousness of success and prosperity in the British Commonwealth.

\section{REFERENCES}

1. Barthes, R. (1989) Izbrannye raboty: Semiotika: Poetika [Selected works: Semiotics: Poetics]. Translated from French. Moscow: Progress.

2. Ankersmit, F. (2003) Narrativnaya logika: Semanticheskiy analiz yazyka istorikov [Narrative Logic: A Semantic Analysis of the Historian's Language]. Translated from English by O. Gavrishina, A. Oleynikov. Moscow: Ideya-Press.

3. Erickson, E. (2006) Identichnost': yunost' i krizis [Identity: youth and crisis]. Translated from English by A.D. Andreeva et al. Moscow: Flinta.

4. Erickson, E. (2008) Krizis identichnosti v avtobiograficheskoy perspektive (fragment iz knigi "Istoriya zhizni i istoricheskiy moment" 1975) [The identity crisis in the autobiographical perspective (a fragment from "The History of Life and the Historical Moment", 1975)]. Lichnost'. Kul'tura. Obshchestvo. 2. pp. 48-59.

5. Anderson, B. (2001) Voobrazhaemye soobshchestva [Imagined communities]. Translated from English by B. Nikolaev. Moscow: KANON-Press; Kuchkovo pole.

6. Gellner, E. (1991) Natsii i natsionalizm [Nation and Nationalism]. Translated from English by T.V. Brednikova, M.K. Tyunkina. Moscow: Progress.

7. Hobsbawm, E. \& Ranger, T. (1992) The Invention of Tradition. Cambridge: Cambridge University Press.

8. Misztal, B. (2003) Teories of remembering. Maidenhead-Philadelfia: Open University Press.

9. Le Goff, J. (1992) Tsivilizatsiya srednevekovogo Zapada [Civilization of the Medieval West]. Translated from French. Moscow: Progress-Akademiya.

10. Ricœur, P. (2004) Pamyat', istoriya, zabvenie [Memory, history, oblivion]. Translated from French. Moscow: Izdatelstvo gumanitarnoy literatury.

11. Hegel, G.V.F. (1993) Filosofiya istorii [Philosophy of History]. Translated from German. St. Petersburg: Nauka.

12. Toshchenko, Zh.T. (2000) Istoricheskoe soznanie i istoricheskaya pamyat': analiz sovremennogo sostoyaniya [Historical consciousness and historical memory: Analysis of the current state]. Novaya i noveyshaya istoriya-Modern and Current History Journal. 4. pp. 3-14.

13. Boyko, V.E., Medushevskiy, A.N., Toshchenko, Zh.T. et al. (2010) Materialy "kruglogo stola", provedennogo po rezul'tatam issledovaniya "Istoricheskaya pamyat' v rossiyskom obshchestve: sostoyanie i problemy formirovaniya" [. Materials of the "round table" discussion on the results of the research "Historical memory in Russian society: the state and problems of formation"]. Sotsiologiya vlasti-Sociology of Power. 6. pp. 47-67.

14. Hübner, K. (2001) Natsiya: ot zabveniya k vozrozhdeniyu [Nation: From Oblivion to Rebirth]. Translated from German by A.Yu. Antonovskiy. Moscow: Kanon+.

15. Zvereva, G.I. (1987) Istoriya Shotlandii [History of Scotland]. Moscow: Vysshaya shkola.

16. Malkin, S.G. (2010) Gornaya Shotlandiya kontsa XVII - pervoy poloviny XVIII veka i romany Val'tera Skotta [Highlands of Scotland at the end of the 17th first half of the 18th centuries and Walter Scott's novels]. Novaya i noveyshaya istoriya-Modern and Current History Journal. 2. pp. 59-71.

17. Reizov, B.G. (1965) Tvorchestvo Val'tera Skotta [Walter Scott's Works]. Moscow: Khudozhestvennaya literatura.

18. Scott, W. (1965) Sobranie sochineniy v dvadtsati tomakh [Collected Works in Twenty Volumes]. Vol. 20. Translated from English by E.T. Tank. Moscow; Leningrad: Khudozhestvennaya literatura.

19. Scott, W. (1939-1946) The Journal of Sir Walter Scott. Vol. 1-3. Edinburgh: Oliver \& Boyd.

20. Vasiliev, A.G. (2015) Kul'turnaya pamyat'/zabvenie i natsional'naya identichnost': teoreticheskie osnovaniya analiza [Cultural memory / oblivion and national identity: the theoretical bases of analysis]. In: Kochelyaeva, N.A. (ed.) Kul'turnaya pamyat' v kontekste formirovaniya natsional'noy identichnosti Rossii v XXI veke [Cultural memory in the context of the formation of the Russian national identity in the 21 st century]. Moscow: Sovpadenie. pp. $29-57$

21. Scott, W. (1828) Tales of a Grandfather; Being Stories Taken from Scottish History. Humbly Inscribed to Hugh Littlejohn, Esq. In Three Vols. Vol. 1. Edinburgh: Cadell \& Co.; London: Simpkin \& Marshall.

22. Glebov, A.G. (2011) Rimskaya Britaniya V III-IV vekakh i ee padenie [The fall of the Roman Britain in the 3rd-4th centuries]. Vestnik Voronezhskogo gosudarstvennogo universiteta - Proceedings of Voronezh State University. 2. pp. 89-92.

23. Drobizhev, L.M. (2013) Grazhdanskaya i religioznaya identichnost': vchera, segodnya, zavtra [Civil and religious identity: yesterday, today, tomorrow]. Moscow: Rosspen.

24. Shnirelman, V.A. (1999) Natsional'nye simvoly, etnoistoricheskie mify i etnopolitika [National symbols, ethnohistorical myths and ethnopolitics]. In: Teoreticheskie problemy istoricheskikh issledovaniy [Theoretical problems of historical research]. Moscow: Moscow State University. pp. $118-147$.

25. Scott, W. (1836) The Prose Works of Sir Walter Scott. Vol. 25. Edinburgh: Cadell.

26. Scott, W. (1992) Rob Roy [Rob Roy]. Tranlsated from English. Moscow: Dom. 